\title{
ANÁLISE QUANTITATIVA DOS DADOS PRESENTES NOS RELATÓRIOS DA OUVIDORIA DA PMSP, DE 2010 A 2014, COM ENFOQUE NO VERDE URBANO.
}

\author{
Marcos Alberto Stanischesk Molnar ${ }^{1}$
}

\begin{abstract}
RESUMO
As Áreas Verdes Urbanas têm sido diretamente afetadas pelo processo de urbanização que ocorreu nas Metrópoles e Centros Urbanos. Além de muitos benefícios para a saúde humana, tais áreas têm promovido melhoria da qualidade de vida para a população, no que diz respeito ao lazer, embelezamento paisagístico e microclima. No entanto, muitas ocorrências têm sido reportadas relativo a problemas com o verde urbano. Isso ocorre por conta da sua dimensão ainda relevante no espaço urbano e a falta de recursos técnicos para a manutenção preventiva, além de outras questões culturais e sociais. Nesse sentido, esse trabalho vem analisar os Relatórios de Ouvidoria do Município de São Paulo buscando entender a dinâmica das ocorrências e protocolos abertos pelos munícipes e eventuais tendências de demanda nas categorias de eventos, bem como a importância e relevância do verde urbano e consequentemente, sua manutenção e planejamento.
\end{abstract}

PALAVRAS-CHAVE: Áreas Verdes Urbanas. Município de São Paulo. Relatórios de Ouvidoria.

\section{QUANTITATIVE ANALYSIS OF DATA IN THESE REPORTS OF OMBUDSMAN PMSP, DE 20102014 WITH FOCUS ON GREEN URBAN.}

\begin{abstract}
The Urban Green Areas has been directly affected by the urbanization process that occurred in the Metropolises and Urban Centers. Besides many benefits to human health, such areas has promoted improvement of quality of life of the population with regard to leisure, landscaped embellishment and microclimate. However, many incidents have been reported concerning the problems with urban green. This happens because of their still relevant dimension in urban spaces and the lack of technical resources for preventive maintenance, and other cultural and social issues. Thus, this work comes to analyze the Ombudsman reports of São Paulo seeking to understand the dynamics of events and

\footnotetext{
${ }^{1}$ Mestrando em Ambiente, Saúde e Sustentabilidade, Faculdade de Saúde Pública da Universidade de São Paulo (USP).marcos.molnar@usp.br.
} 
Revista Nacional de

Gerenciamento de Cidades

protocols opened by residents and possible demand trends in the categories of events, well as the importance and relevance of urban green and consequently their maintenance and planning.

KEYWORDS: Urban Green Areas. Municipality of São Paulo. Ombudsman reports.

\title{
ANÁLISIS CUANTITATIVO DE DATOS EN ESTOS INFORMES DE DEFENSOR DEL PUEBLO PMSP, DE 2010 2014 CON EL FOCO EN VERDE URBANO.
}

\begin{abstract}
RESUMEN
Las Áreas verdes urbanas han sido directamente afectadas por el proceso de urbanización que ocurrió en las metrópolis y centros urbanos. Además de muchos beneficios para la salud humana, tales áreas ha promovido la mejora de la calidad de vida de la población en relación con el ocio, embellecimiento paisajístico y el microclima. Sin embargo, han sido reportados muchos incidentes acerca de los problemas con el verde urbano. Esto sucede debido a su dimensión aún relevante en los espacios urbanos y la falta de recursos técnicos para el mantenimiento preventivo, y tambien de otras cuestiones culturales y sociales. Por lo tanto, este trabajo trata de analizar los informes de la Defensoría de São Paulo en busca de comprender la dinámica de los acontecimientos y protocolos abiertos por los residentes y las posibles tendencias de la demanda en las categorías de eventos, así como la importancia y relevancia de verde urbano y en consecuencia, su mantenimiento y la planificación .
\end{abstract}

PALABRAS CLAVE: Áreas Verdes Urbanas. Municipio de São Paulo. Informes de Defensoría.

\section{INTRODUÇÃO}

O processo de urbanização tem sido um fator transformador de demasiada importância na história do país, alterando espacial e socialmente as paisagens brasileiras. Segundo Deák e Schiffer (1999, p. 11), "em um pouco mais de uma geração, o Brasil se transformou de um país predominantemente agrário em um país visivelmente urbanizado". Ou seja, o que antes era, em sua maior parte, uma paisagem natural passa a ter sua organização espacial baseada na dinâmica do capital, na qual a infraestrutura é fundamental para a reprodução do mesmo (HARVEY, 1978). 
Revista Nacional de

Gerenciamento de Cidades

Dessa forma, com a expansão das áreas urbanizadas ocorre uma mudança estrutural no meio natural, levando à alteração ou apropriação deste e subvertendo os elementos para funcionarem segundo a lógica urbana. Nesse sentido, pode se destacar alguns exemplos como a utilização dos rios e córregos para deposição de dejetos, além da devastação das áreas verdes que acabam dando lugar à itens que compõem o meio urbano com cada vez mais áreas construídas e impermeabilizadas. (JACOBI, 2006).

Nessa perspectiva, Di Giulio e Vasconcellos (2014) afirmam que:

\begin{abstract}
os aglomerados urbanos demandam "bens naturais" para sua própria sobrevida, com vistas a garantir abastecimento de água, iluminação pública, abastecimento alimentar, transporte público, segurança pública, soluções para os resíduos gerados, diretrizes para ocupação e uso do solo e negociação de interesses múltiplos (e, em sua maior parte, conflitantes). As cidades e seus habitantes são geradores de problemas e soluções com racionalidades próprias. (DI GIULIO; VASCONCELLOS, 2014).
\end{abstract}

No Brasil, o processo de urbanização das cidades ocorreu com uma velocidade, de certa forma, bastante acentuada, comparado com países capitalistas mais desenvolvidos (BRITO; SOUZA, 2005). Num primeiro momento, tal rapidez fez com que este processo ocorresse sem um planejamento urbano específico voltado para essa demanda (PSILLAKIS, 1977) e sem um planejamento ambiental.

No município de São Paulo a expansão urbana ocorreu em direção às várzeas e terraços fluviais, onde anteriormente haviam sido instaladas as ferrovias. Espaços anteriormente vazios passaram a ser ocupados por fábricas e bairros operários (SEABRA, 1987). A região central da cidade passou a configurar-se como setor de serviço e comércio. (SMVA; SEMPLA, 2004)

Segundo Sepe e Takiya (2004), os primeiros planos urbanos do município tinham como maior preocupação questões estéticas e de higiene, como por exemplo, o Código de Posturas de 1886, redigido como uma legislação urbanística, não tendo por base, diretrizes gerais de uso e ocupação do solo. Estabelecia largura 
Revista Nacional de

Gerenciamento de Cidades

mínima das vias de circulação e localização de algumas atividades como teatros, hospitais, indústrias e seus horários de funcionamento.

Posteriormente, conforme descrito no Atlas Ambiental do Município de São Paulo (SMVA; SEMPLA, 2004), a partir do Plano de Avenidas de Prestes Maia ocorreu a elaboração de diretrizes para aspectos viários, localização de edifícios públicos e áreas verdes, indicando um índice de área verde por habitante (que na época era de $0,71 \mathrm{~m} 2 / \mathrm{hab}$.) e propondo a implantação de parques urbanos, como por exemplos: Cabeceiras do Ipiranga, Ibirapuera, Butantã e Aclimação, entre outros, ainda com o viés de embelezamento.

As temáticas ambientais adquiriram mais força na gestão de políticas públicas após a conferência Mundial da ONU sobre o Meio Ambiente Humano, realizada em Estocolmo no ano de 1972, e no Brasil principalmente com a Rio 92.

Nessa perspectiva Jacobi (2006) coloca:

Apesar de existir um quadro que preocupa pela sua complexidade e pelas dificuldades de gerar respostas mais efetivas, observam-se alguns movimentos e empenho do poder público na formulação e implementação de políticas, planos, programas e projetos que enfatizam o controle ambiental. Nesse sentido observam-se intervenções físicas diretas em ambientes degradados e aprimoramento nas operações regulares e uma gradual ampliação de atividades de natureza sociocultural, educativa, e participativa, tanto em nível municipal como estadual. (JACOBI, 2006 p.125)

Porém, a gestão dos riscos ambientais não é feita de forma adequada no Brasil, ocorrendo de forma mais morosa e menos eficiente, utilizando instrumentos impróprios para a gestão urbana (SILVA; MACHADO, 2001). Parte disso se deve pelo tamanho das grandes cidades e da quantidade de eventos gerados.

Referente ao Município de São Paulo, Di Giulio e Vasconcellos (2014) dizem que:

São Paulo demonstra, na prática, atrasos e fragilidades tanto em termos de desenvolvimento de tecnologias sociais como de atenção dos poderes 
públicos em acompanhar o crescimento urbano e propor ações voltadas ao ordenamento territorial. Como consequência, a capital paulista exemplifica os principais desafios encontrados nos ambientes urbanos, impostos cotidianamente aos gestores e à população residente... (DI GIULIO; VASCONCELLOS, 2014 p. 45)

Um exemplo disso é a gestão das áreas verdes no espaço urbano, em especial a arborização urbana. Rossetti et al. (2010) afirmam que: "A grande maioria das cidades brasileiras, São Paulo entre elas, não conta com um planejamento prévio de sua arborização...".

Além disso, o poder público, no que tange a gestão e manutenção do verde urbano no município paulista, tem se mostrado ineficiente e omisso. Uma reportagem feita pelo jornal Folha de São Paulo, em 24 de dezembro de 2014, mostra que a situação é crítica em boa parte da cidade, com muitas árvores doentes, podres e mortas. Isso inclusive acarretou na morte de um indivíduo que estava dentro de um veiculo, após queda de árvore (GERAQUE, 2014).

A mesma reportagem informa que segundo levantamento do IPT, em alguns bairros, como os Jardins, cerca de $15 \%$ delas já estão condenadas e dessa forma, se tornam um risco eminente para os transeuntes e a população residente.

Segundo notícia divulgada pelo Portal da Rede Globo, do dia 17/02/2015, a Prefeitura de São Paulo registrou a queda de 1.765 árvores de novembro de 2014 até o início de fevereiro de 2015, gerando muitos transtornos no ponto de vista da circulação e levando risco para os indivíduos que por lá passavam (MELLO, 2015).

O cadastro de ocorrências relativas ao verde urbano no Município de São Paulo é feito através de 3 canais: central telefônica 156, canal web SAC e contato com a subprefeitura da região. Todas essas informações são monitoradas e catalogadas pela ouvidoria da Prefeitura do Município de São Paulo, e executadas pela Secretaria Municipal de Coordenação das Subprefeituras (SMSP).

Dentre os tipos de ocorrências mais protocoladas pela SMSP estão as ocorrências de Jardinagem. Segundo o website da Prefeitura estão entre as atividades classificadas nessa categoria as seguintes atividades: desinsetização de árvores, capinação, corte irregular, neutralização de raízes arbóreas, limpeza de 


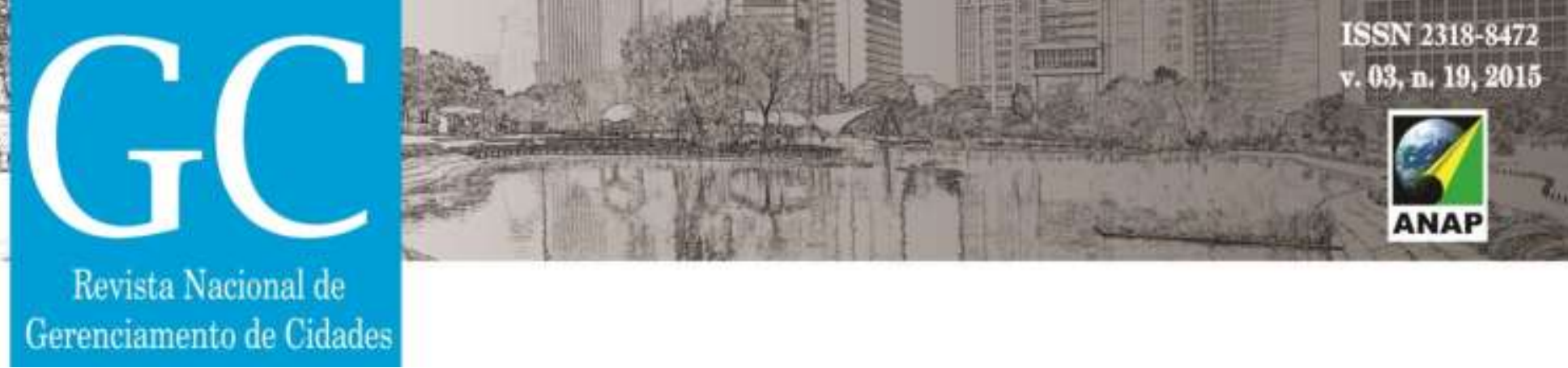

áreas ajardinadas, conservação de áreas verdes, plantio, remoção, poda e transplante de árvores, instalação de "protetor" nas espécies. (http://www.prefeitura.sp.gov.br/cidade/secretarias/saude/ouvidoria/index.php?p=186 89 acesso em: 20/05/2015)

Nesse contexto, a análise dos dados de ocorrências relativas ao verde urbano, especialmente em São Paulo, se faz necessária para o melhor entendimento e novas proposições de como lidar com essa questão no âmbito da gestão de serviços urbanos.

\section{OBJETIVOS}

\subsection{Objetivo Geral}

- Analisar os relatórios de ouvidoria da Prefeitura do Município de São Paulo para avaliar a quantidade de requisições relativas ao verde urbano e sua variação no período de 5 anos.

\subsection{Objetivos Específicos}

- Analisar o volume dos principais grupos de protocolos abertos pelos canais da ouvidoria do Município de São Paulo.

- Verificar quais são os grupos de ocorrências mais frequentes, a partir dos protocolos indicados pelos Relatórios de Ouvidoria.

\section{MÉTODOS}

\subsection{Definição da Área de estudo}

O Município de São Paulo é uma das maiores cidades do mundo no que diz respeito à população (está na sexta posição de acordo com os dados dos últimos 


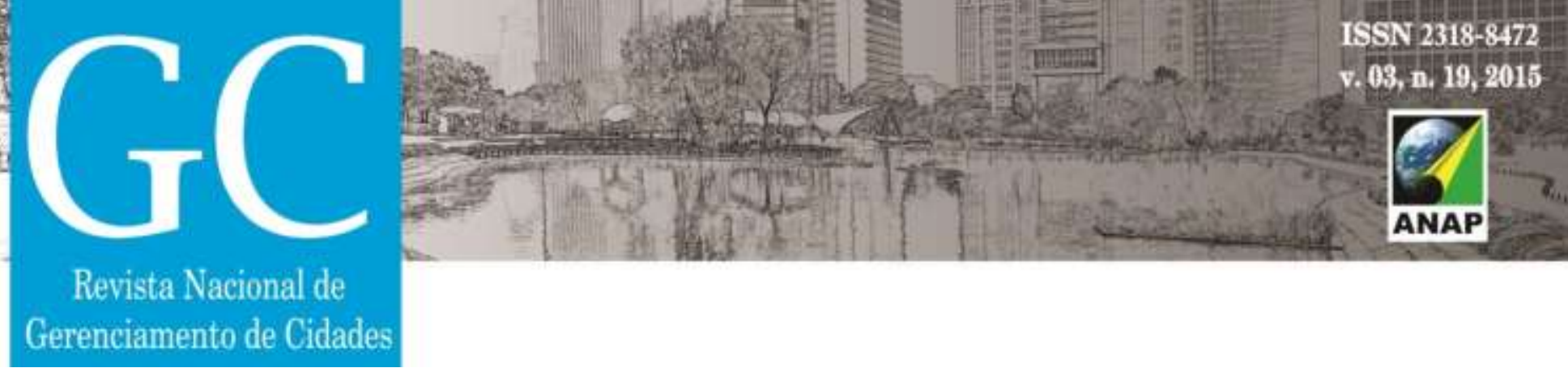

censos) e o mais importante centro econômico do país, tendo em seu território a Bolsa de Valores (BOVESPA) e um PIB de mais de 380 milhões (IBGE, 2009).

Conta com uma área de 1523,3 km² na qual está inserida uma população de 11.253.503 habitantes, com uma concentração média de 7.387,69 habitantes $/ \mathrm{km}^{2}$, segundo dados do último Censo realizado pelo Instituto Brasileiro de Geografia e Estatística (CENSO 2010 - IBGE).

Dada sua relevância dentro do Brasil, o município foi escolhido como área de estudo, também por conta de seu território altamente urbanizado e das áreas verdes remanescentes e novas que fazem parte da paisagem da cidade, se integrando com as dinâmicas metropolitanas.

As coordenadas geográficas são: $23^{\circ} 32^{\prime} 51^{\prime \prime}$ de Latitude Sul e $46^{\circ} 38^{\prime} 10^{\prime \prime}$ de Longitude W de Greenwich, com altitude média de 760 metros (SMVA; SEMPLA, 2004).

Na figura 1, podemos ver a localização espacial do município em relação ao Estado de São Paulo e Brasil. Do lado direito, em vermelho, aparecem as áreas de subprefeituras. Essas áreas foram utilizadas como unidade territorial por conta da divulgação dos dados pela Prefeitura Municipal de São Paulo, que seguem essa determinação. 


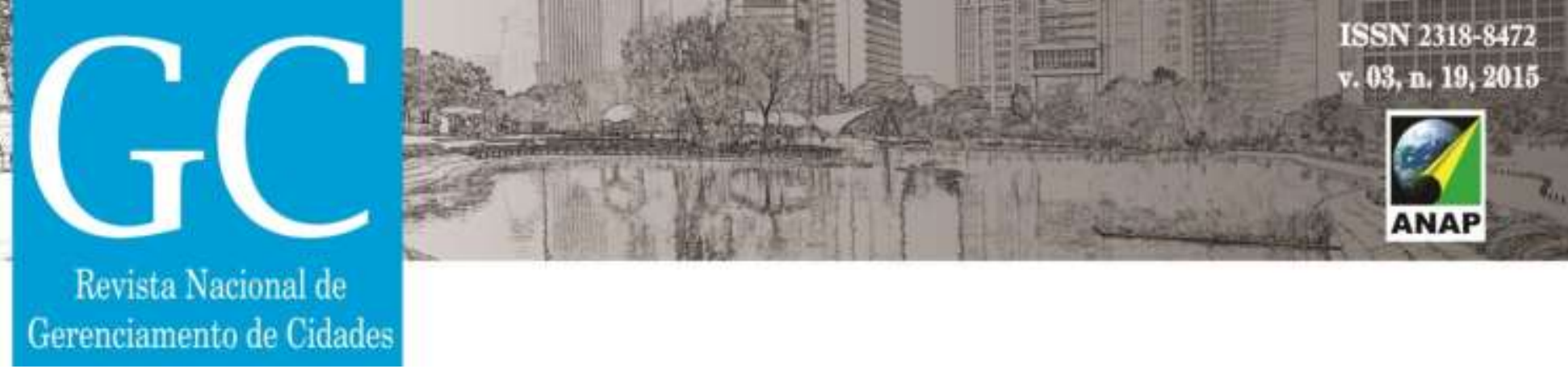

Figura 1: Mapa de Localização da Área de Estudo

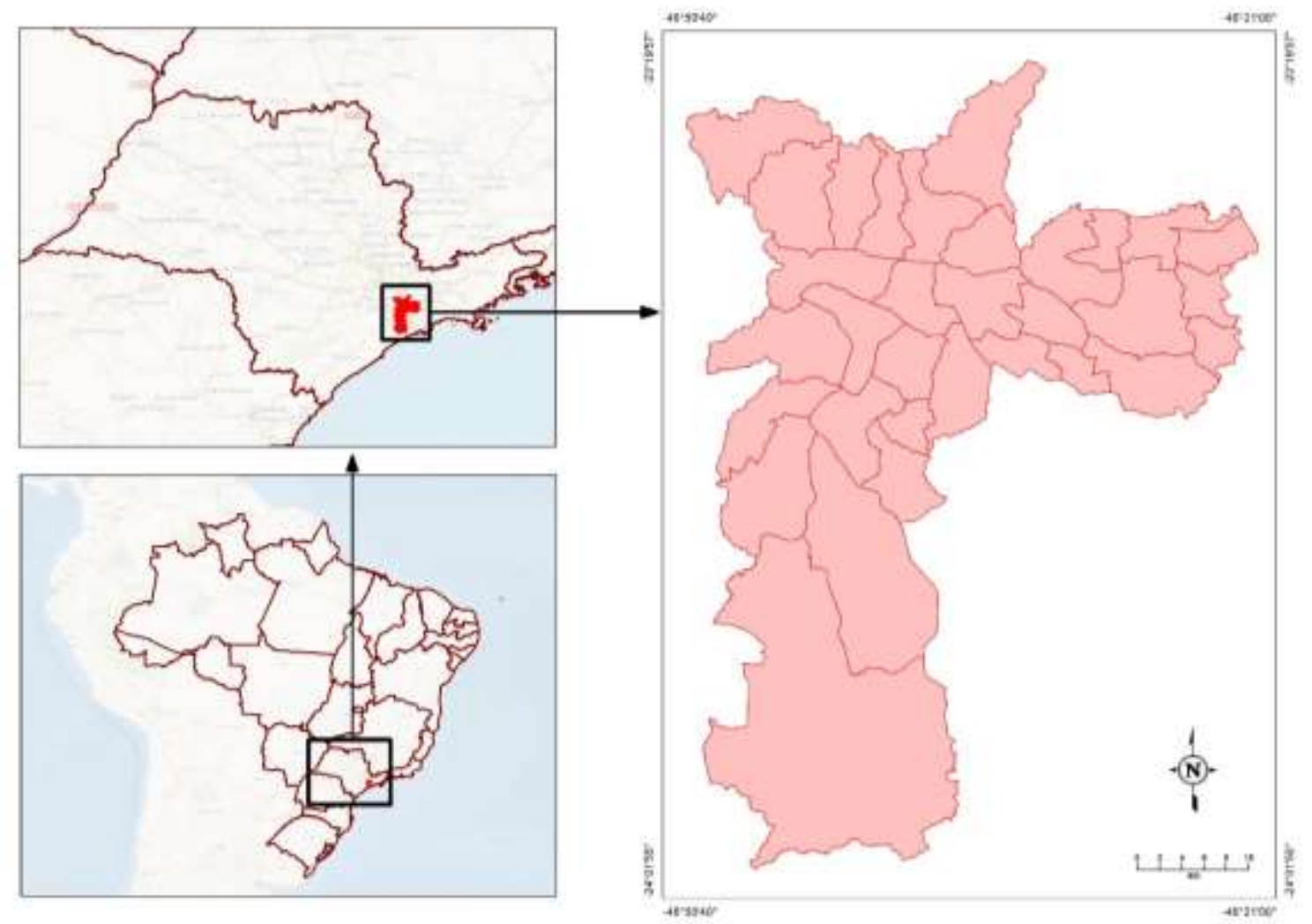

Fonte: Elaboração Própria

\subsection{Tipo de estudo e Materiais}

Para esse artigo foi feita uma análise documental a partir dos Relatórios de Ouvidoria, disponibilizados pela Prefeitura do Município de São Paulo, dos anos 2010 até 2014, buscando os dados relativos aos protocolos abertos, nos três canais disponíveis para os cidadãos e catalogados pela Ouvidoria, nos respectivos anos categorizados pelo tipo de ocorrência.

Tais relatórios estão disponíveis para consulta e descarga dos arquivos digitais no Portal da Prefeitura do Município de São Paulo (http://www.prefeitura.sp.gov.br/cidade/secretarias/ouvidoria/relatorios_anuais/index. php? $\mathrm{p}=473$ ), e foram acessados no dia 20/05/2015. 


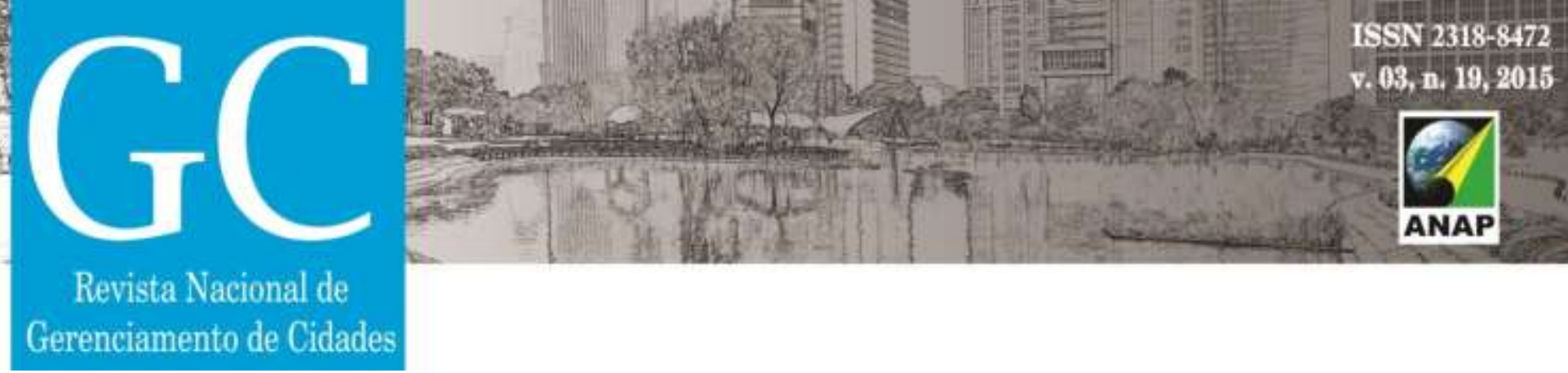

\subsection{Análise dos dados}

As requisições abertas pelos três canais disponíveis são monitoradas e disponibilizadas em um Relatório da Ouvidoria. Esse material contendo todas essas demandas será analisado por esse trabalho.

Nos relatórios os dados são classificados pela quantidade de protocolos abertos nas dez categorias mais atendidas; no entanto, para esse estudo foram consideradas apenas as oito que apareciam em todos os documentos estudados. Esses valores foram computados e inseridos em formato tabular através do Software Microsoft Excel versão 2014.

Posteriormente, foi elaborado um gráfico com a variação desses valores no decorrer no período, dando ênfase para a categoria de jardinagem. A categoria Atendimento foi retirada da comparação no gráfico por ser considerada qualitativa e mais genérica, abrangendo toda a parte de qualidade de atendimento dos serviços públicos, porém foi mantida na tabela com os valores médios e medianas por categoria.

É importante frisar que os relatórios trazem dados generalizados, definindo muito pouco sobre as ocorrências, trazendo apenas sua categorização nos grupos e as três categorias mais recorrentes em cada subprefeitura.

\section{RESULTADOS}

Após análise dos documentos foram montadas algumas representações tabulares e gráficas que facilitassem a visualização da dispersão de ocorrências protocoladas pelos munícipes durante o período estudado.

Na Tabela 1 foi feita uma sintetização dos valores absolutos das quantidades de protocolos abertos por categoria e ano, elencados de forma decrescente pelos valores encontrados no ano de 2014.

Tabela 1: Variação da quantidade de Protocolos abertos por categoria no período estudado 


\begin{tabular}{|cccccc|}
\hline Categoria & $\mathbf{2 0 1 0}$ & $\mathbf{2 0 1 1}$ & $\mathbf{2 0 1 2}$ & $\mathbf{2 0 1 3}$ & $\mathbf{2 0 1 4}$ \\
\hline Atendimento & 1.945 & 1.751 & 2.125 & 1.265 & 1.827 \\
Jardinagem & 1.262 & 1.082 & 886 & 1.192 & 1.314 \\
Via pública/ logradouro & 813 & 580 & 432 & 984 & 1.166 \\
Trânsito & 352 & 376 & 600 & 850 & 1.102 \\
Perturbação do silêncio & 536 & 536 & 590 & 920 & 917 \\
Transporte público & 545 & 403 & 437 & 524 & 874 \\
Limpeza pública/ lixo & 579 & 580 & 407 & 624 & 717 \\
Iluminação pública & 2.397 & 2.807 & 1.351 & 750 & 689 \\
\hline Total de Protocolos Abertos & $\mathbf{1 4 . 8 3 4}$ & $\mathbf{1 2 . 5 5 8}$ & $\mathbf{1 1 . 9 2 9}$ & $\mathbf{1 3 . 6 2 2}$ & $\mathbf{1 7 . 3 4 1}$ \\
\hline
\end{tabular}

Fonte: Relatórios de Ouvidoria - PMSP $(2010,2011,2012,213,214)$. Elaboração própria.

A partir da Tabela 1, pode-se observar que a quantidade de protocolos abertos por ano variou de cerca de 12 mil até pouco mais de 17 mil no período. As ocorrências com maior recorrência foram as relativas ao atendimento de órgãos públicos municipais.

Para facilitar a análise foi construído um gráfico de linhas e área com a variação de ocorrências pelas categorias (Gráfico 1). No entanto, os dados referentes à categoria Atendimento não foram computados, uma vez que são de origem qualitativa e podem demonstrar a insatisfação do usuário do sistema público com diversos segmentos e por diversos motivos.

O gráfico foi composto por linhas representando a variação da quantidade de ocorrências pelo período, destacando na cor verde com maior espessura a categoria de Jardinagem, por se tratar do objeto de estudo desse trabalho. O total de protocolos abertos é representado pela área, de textura cinza, ao fundo utilizando o eixo secundário para o intervalo de dados.

O que se consegue notar num primeiro momento é que lluminação Pública tem a maior variação entre as categorias estudadas, tendo o número de ocorrências acima de 2300 no ano de 2010 , elevando-se para mais de 2800 protocolos abertos em 2011, porém caindo em 2012 para menos da metade do valor (cerca de 1350) e continuando sua trajetória de queda nos dois anos seguintes (750 no ano de 2013 e 


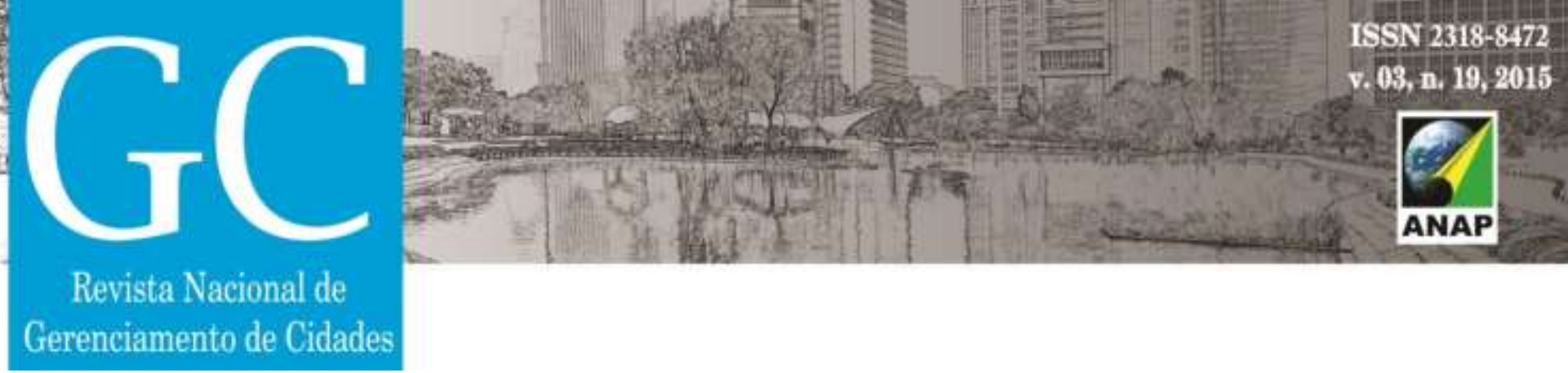

o primeiro lugar no número de protocolos. Mesmo antes de ocupar essa posição a Jardinagem já apresentava valores bastante representativos.

Para analisar esse assunto foram elaboradas mais duas tabelas com as médias e medianas das ocorrências no período (Tabela 2 e Tabela 3).

Tabela 2: Média e Mediana da quantidade de Protocolos abertos por categoria

\begin{tabular}{|ccc|}
\hline Categoria & Média - 5 anos & Mediana - 5 anos \\
\hline Atendimento & 1.783 & 1.827 \\
Iluminação pública & 1.599 & 1.351 \\
Jardinagem & $\mathbf{1 . 1 4 7}$ & $\mathbf{1 . 1 9 2}$ \\
Via pública/ logradouro & 795 & 813 \\
Trânsito & 656 & 600 \\
Perturbação do silêncio & 700 & 590 \\
Limpeza pública/ lixo & 581 & 580 \\
Transporte público & 557 & 524 \\
\hline Total de Protocolos Abertos & $\mathbf{1 4 . 0 5 7}$ & $\mathbf{1 3 . 6 2 2}$ \\
\hline
\end{tabular}

Fonte: Relatórios de Ouvidoria - PMSP (2010, 2011, 2012, 213, 214). Elaboração própria.

Tabela 3: Média da quantidade e percentual de Protocolos abertos por categoria

\begin{tabular}{|ccc|}
\hline Categoria & \multicolumn{2}{c|}{ Média - 5 anos } \\
& Quantidade & Percentual \\
\hline Atendimento & 1.783 & $12,68 \%$ \\
Iluminação pública & 1.599 & $11,37 \%$ \\
Jardinagem & $\mathbf{1 . 1 4 7}$ & $\mathbf{8 , 1 6 \%}$ \\
Limpeza pública/ lixo & 581 & $4,14 \%$ \\
Perturbação do silêncio & 700 & $4,98 \%$ \\
Trânsito & 656 & $4,67 \%$ \\
Transporte público & 557 & $3,96 \%$ \\
Via pública/ logradouro & 795 & $5,66 \%$ \\
\hline Protocolos & $\mathbf{1 4 . 0 5 7}$ & $\mathbf{1 0 0} \%$ \\
\hline
\end{tabular}

Fonte: Relatórios de Ouvidoria - PMSP (2010, 2011, 2012, 213, 214). Elaboração própria. 


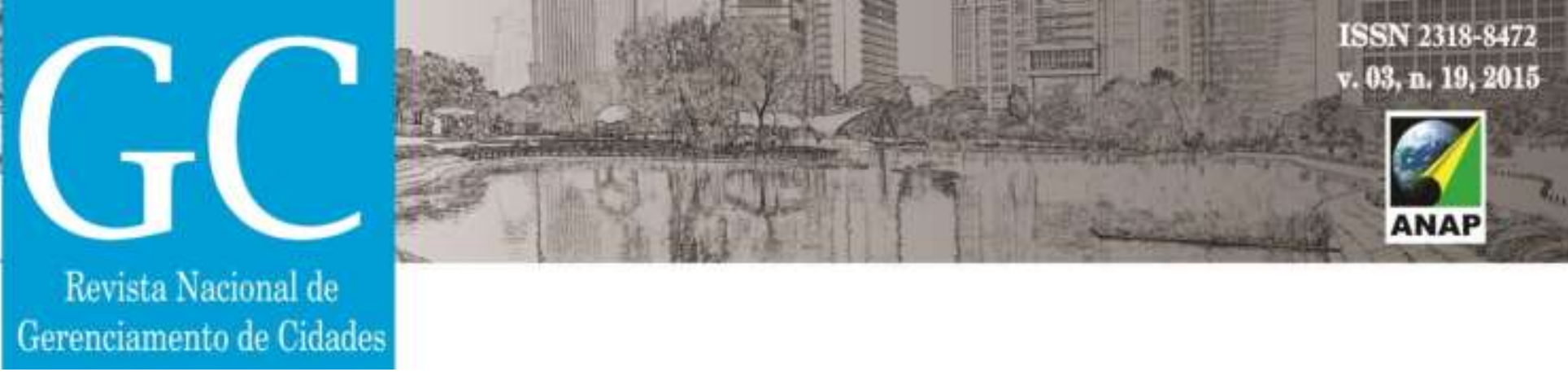

\section{CONSIDERAÇÕES FINAIS}

Embora as áreas verdes tenham diminuído, por conta do processo de urbanização, ainda são um importante fator dentro da dinâmica da cidade, podendo influenciar de forma positiva através dos benefícios promovidos pelo verde dentro do ambiente urbano, ou de forma negativa, principalmente quando não ocorre uma manutenção adequada. Dessa forma, o estudo das ocorrências de serviços urbanos nos permite um olhar sobre as alterações na paisagem e sua influência na vida da população.

Os documentos analisados não nos permitem fazer um diagnóstico sobre a resolução das requisições, porém nos indicam uma demanda sempre presente de uma série de serviços urbanos, em especial os casos envolvendo a categoria Jardinagem. Tais ocorrências, no último verão, provocaram muitos estragos para o Município de São Paulo, além de oferecerem riscos a população mais próxima.

A criação de novos mecanismos que permitam uma maior interação da população com a gestão pública pode ser um instrumento de grande valia para diminuição e prevenção desses riscos, envolvendo principalmente a arborização urbana, que podem impactar diretamente no bem-estar, na qualidade de vida e saúde humana (JACOBI, 2006).

No entanto, isso deve vir acompanhado previamente de um conhecimento em Educação Ambiental. Tal conhecimento alertaria os indivíduos para os riscos aos quais estão inseridos, o modo de identificá-los e até mesmo prevení-los, transformando a própria população em agentes parceiros do poder público.

Nesse contexto, a utilização de tecnologias sociais que permitam uma maior interação da população com a gestão pública pode ser um instrumento de grande valia para diminuição e prevenção desses riscos, que podem ter impacto direto no bem-estar, na qualidade de vida e saúde humana (DI GIULIO; VASCONCELLOS, 2014).

\section{REFERÊNCIAS}

BRASIL. IBGE. Perfil dos municípios brasileiros: 2009. Brasília, 2010 
Revista Nacional de

Gerenciamento de Cidades

BRASIL. IBGE. Pesquisa Nacional por Amostra de Domicílio - PNAD. Brasília, 2013.

BRASIL. IBGE. Censo Demográfico 2010. Brasília, 2012.

BRITO, F., SOUZA, J. 2005. Expansão urbana nas grandes metrópoles: o significado das migrações intrametropolitanas e da mobilidade pendular na reprodução da pobreza. São Paulo em Perspectiva, vol. 19, n.4.

DEÁK, C; SCHIFFER, S.R. (org.) O processo de urbanização no Brasil. São Paulo: EDUSP, 1999.

DI GIULIO, G.M. and VASCONCELLOS, M.P. Contribuições das Ciências Humanas para o debate sobre mudanças ambientais: um olhar sobre São Paulo. Estud. av. [online]. 2014, vol. 28, oㅡ 82, p. 41-63. [viewed December 16th 2014]. ISSN 0103-4014. DOI: 10.1590/S0103-40142014000300004.

GERAQUE, E. Prefeitura de São Paulo falha em conter queda de árvore em época de chuvas.

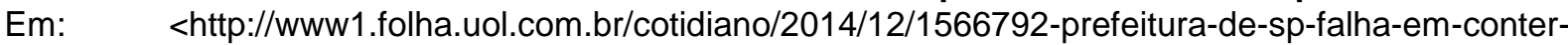
queda-de-árvore-em-epoca-de-chuvas.shtml>. Acesso em: 29/04/2015

JACOBI, P. R. Dilemas Socioambientais na Gestão Metropolitana: do risco à busca da sustentabilidade urbana. Revista de Ciências Sociais ISSN 0104-8015 Política; trabalho n.25 Outubro de 2006 - p. $115-134$.

HARVEY, D. La Geografia de la acumulacion capitalista: una reconstrucción de la teoria marxista. In: GARCIA, M.D. (ed.). La Geografia Regional Anglosajona. Bellaterra: Universidad Antonina de Barcelona. 1978 - p.143 -181

MELLO, Z. Mais de 1.700 árvores caíram em São Paulo nos últimos três meses. Em: $<$ http://g1.globo.com/sao-paulo/noticia/2015/02/mais-de-1700-árvores-cairam-em-sao-paulo-nosultimos-tres-meses.html>, Acesso em: 29/04/2015

NUCCI, J.C. Qualidade ambiental e adensamento urbano. Humanitas, São Paulo - SP, 2001.

PSILLAKIS, Homero Miguel. Mercado imobiliário versus varejo: um estudo de sua evolução. Rev. adm. empres. [online]. 1977, vol.17, n.1, pp. 7-20. ISSN 0034-7590.

ROSSETTI, A.I.N.; PELLEGRINO, P.R.M,; TAVARES, A.R. As árvores e suas interfaces no ambiente urbano. Revista da Sociedade Brasileira de Arborização Urbana, Piracicaba, v. 5, n. 1, p. 1-24, 2010.

SEABRA, O. Os meandros dos rios nos meandros do poder: Tietê e Pinheiros, valorização dos rios e das várzeas na cidade de São Paulo. São Paulo, 1987. Tese (Doutorado em Geografia) Faculdade de Filosofia, Letras e Ciências Humanas, Universidade de São Paulo.

SÃO PAULO (Município) Ouvidoria Geral; Prefeitura Municipal De São Paulo. Relatório Anual 2010 Ouvidoria Geral PMSP. São Paulo, 2010. Disponível em http://www.prefeitura.sp.gov.br/cidade/secretarias/upload/chamadas/anualogm2010ve_1302724267.p df. Acesso em 05/05/2015.

SÃO PAULO (Município) Ouvidoria Geral; Prefeitura Municipal De São Paulo. Relatório Anual 2011 Ouvidoria Geral PMSP. São Paulo, 2011. Disponível em http://www.prefeitura.sp.gov.br/cidade/secretarias/upload/chamadas/relanual2011_1331059244.pdf. Acesso em 05/05/2015. 


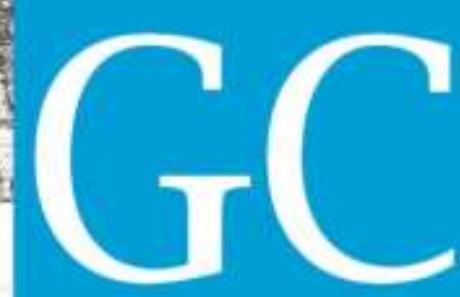

SÃO PAULO (Município) Ouvidoria Geral; Prefeitura Municipal de São Paulo. Relatório Anual 2012 Ouvidoria Geral PMSP. São Paulo, 2012. Disponível em http://www.prefeitura.sp.gov.br/cidade/secretarias/upload/chamadas/relatorio2012_1363815783.pdf. Acesso em 05/05/2015.

SÃO PAULO (Município) Ouvidoria Geral; Prefeitura Municipal de São Paulo. Relatório Anual 2013 Ouvidoria Geral PMSP. São Paulo, 2013. Disponível em http://www.prefeitura.sp.gov.br/cidade/secretarias/upload/ouvidoria/planilha_2013.ods. Acesso em 05/05/2015.

SÃO PAULO (Município) Ouvidoria Geral; Prefeitura Municipal de São Paulo. Relatório Anual 2014 Ouvidoria Geral PMSP. São Paulo, 2014. Disponível em http://www.prefeitura.sp.gov.br/cidade/secretarias/upload/ouvidoria/Planilha\%202014.ods. Acesso em 05/05/2015.

SÃO PAULO (Município) Secretaria do Verde e do Meio Ambiente (SVMA), Secretaria De Planejamento (SEMPLA), Prefeitura Municipal De São Paulo. Atlas Ambiental do Município de São Paulo. São Paulo, 2004. Disponível em http://atlasambiental.prefeitura.sp.gov.br/. Acesso em 09/02/2015.

SEPE, P. M.; TAKIYA, H. Atlas Ambiental do Município de São Paulo: o verde, o território, o ser humano. São Paulo: Secretária de Meio Ambiente, 2004.

SILVA, R.T; MACHADO L. Serviços urbanos em rede e controle público do subsolo: novos desafios à gestão urbana. São Paulo em perspectiva, 15 (01); 2001. 